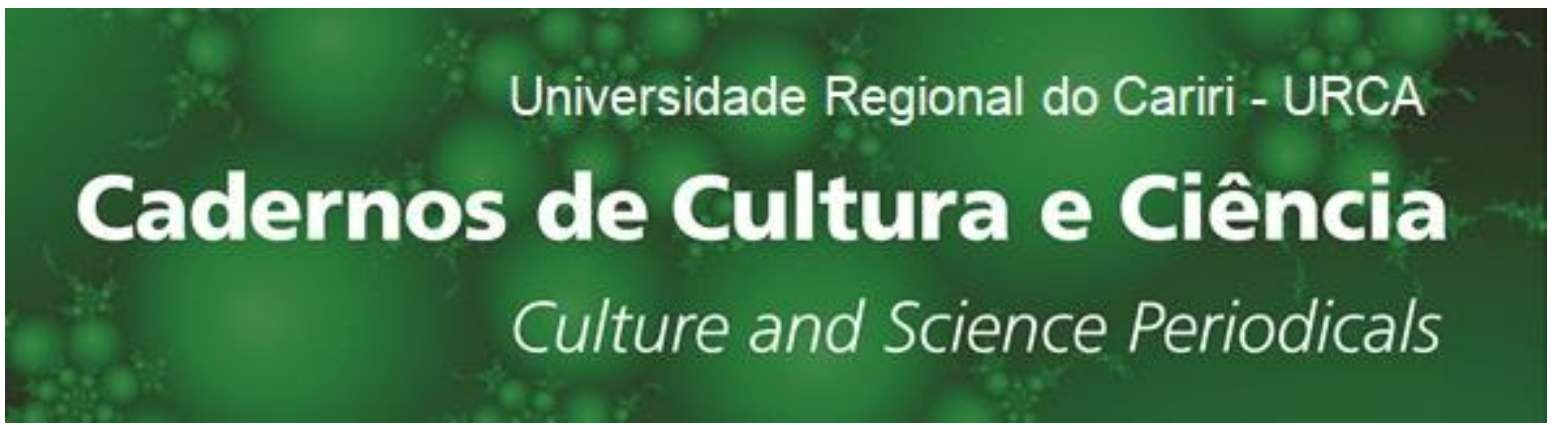

\title{
ESTÉTICA E INTERCULTURA: GRAFITE E TOLERÂNCIA NA UNIVERSIDADE
}

\author{
Domingos Sávio de Almeida Cordeiro ${ }^{1 *}$; João Batista de Albuquerque Figueiredo ${ }^{2}$
}

\begin{abstract}
Resumo: O objetivo deste trabalho é narrar uma intervenção estética e intercultural no Campus Pimenta da Universidade Regional do Cariri - URCA, ocorrida entre outubro de 2017 e janeiro de 2018. Introdução: De maneira geral, a universidade pública espelha o que acontece na sociedade em que ela está inserida, tanto do ponto de vista político, quanto social. Localizada no Ceará a URCA tem num dos campi as paredes continuamente pichadas por alunos. As pichações trazem palavras de ordem contra o poder estabelecido, provocações e insultos. As pichações têm gerado uma disputa pelo espaço visual numa guerra de cores, símbolos, textos e rabiscos. Até meados de 2017 a administração dos campi pintava inúmeras vezes as fachadas e, em curto tempo, surgiam novas pichações. Metodologia: Foi organizada uma campanha com mote "Grafite Tolerância", propondo uma alternativa de debate via realização de murais nas paredes do campus. Resultados: Como resultado alunos, professores e pessoas da comunidade realizaram 64 murais medindo entre um e 30 metros quadrados nas paredes do Campus Pimenta. Considerações: observa-se a presença de visitantes para apreciar as obras; o surgimento de diálogos sobre as obras entre professores e alunos da graduação e da pós-graduação, diminuição do número e frequência de pichações e inúmeros depoimentos informando que o ambiente está mais harmônico e pacificado a partir da realização das obras interculturais.
\end{abstract}

Palavras-chave: Tolerância; Interculturalidade; Descolonialidade; Grafite.

\section{AESTHETICS AND INTERCULTURE: GRAPHITE AND TOLERANCE AT THE UNIVERSITY}

\begin{abstract}
This work has the goal of describing an aesthetic and intercultural intervention in the Pimenta Campus of the Universidade Regional do Cariri - URCA, which occurred between October 2017 and January 2018. Introduction: In general, the public university reflects what happens in the society in which it is inserted, both politically and socially. Located in Ceará, the URCA has a campus whose walls were continuously plastered by students. The graffiti brought slogans against established power, taunts and insults. The graffiti have generated a dispute for the visual space in a war of colors, symbols, texts and scribbles. Until the middle of 2017, the administration of the campuses painted the facades countless times, however, in a short time, new graffiti appeared. Methodology: A campaign was organized with the motto
\end{abstract}

\footnotetext{
${ }^{1}$ Doutor em sociologia, professor do Departamento de Ciências Sociais, Universidade Regional do Cariri - Crato - CE. saviocordeiro@gmail.com

${ }^{2}$ Doutor em educação, professor do Programa de Pós Graduação em Educação Brasileira Universidade Federal do Ceará Fortaleza-CE. joaofigueiredo@hotmail.com

*Autor Correspondente: saviocordeiro@gmail.com

Enviado: 12/05/2018

Aceito: 3/07/2018
} 
"Grafite Tolerância", proposing the possibility of debate through realization of visual arts on the walls of the campus. Results: As a result, students, professors and community members made 64 murals measuring between one and 30 square meters on the walls of Campus Pimenta. Considerations: it was observed the coming of visitors to appreciate the art works; the emergence of dialogues about the works between professors and undergraduate and graduate students, a reduction in the number and frequency of graffiti and countless testimonies informing that the environment is more harmonious and pacified with the accomplishment of the intercultural works.

Keywords: Tolerance; Interculturality; Descolonialidade; Graphite.

\section{Introdução}

$\mathrm{Na}$ universidade existe uma grande heterogeneidade, característica da sociedade brasileira, que pressupõe a interação entre pessoas de diferentes bases culturais. A história recente das instituições de ensino superior tem sido cenário de tensões e conflitos decorrentes da falta de formação política e educacional sobre questões relativas às desigualdades sociais e a alteridade.

Em sentido latu, o desrespeito refere-se a atos de preconceito baseado na ideologia da superioridade de um conjunto da população sobre outro, aqui considerando especificamente o espaço institucional onde se expressam preconceitos contra negros e indígenas, preconceito contra mulheres e pessoas LGBTs (homofobia) e preconceito cultural que ressalta a superioridade entre as culturas segundo crenças, religião, costumes, línguas e tradições. Onde há o desrespeito ao diferente nos meios acadêmicos? Como lidar com a ausência de alteridade nos que fazem a universidade? Para pensar essas questões é importante retomar a gênese da formação social brasileira como ex-colônia portuguesa e suas implicações na produção do conhecimento em universidades. Boaventura de Souza Santos (2009) considera que, nos dois últimos séculos, o campo do conhecimento foi dominado por uma epistemologia que eliminou a reflexão sobre o contexto cultural e político da produção e reprodução do conhecimento, com enormes consequências na descontextualização da produção de saberes.

Nesse texto a noção de epistemologia é tomada como todo entendimento ou ideia "sobre as condições do que conta como conhecimento válido. Por meio do conhecimento válido uma experiência social é inteligível. 'Não há, pois, conhecimento sem práticas e atores sociais. E como umas e outros não existem senão no interior de relações sociais, diferentes tipos de relações sociais podem dar origem a diferentes epistemologias" (NASCIMENTO, 2018, on line). Em qualquer disciplina acadêmica, nas universidades brasileiras, o conhecimento epistemológico e a 
formulação dos métodos científicos, marcam a gênese das ciências como a conhecemos no iluminismo e na ciência moderna.

É bem sabido nos meios acadêmicos o quanto as correntes de pensamento, frequentemente praticadas, têm matriz exclusivamente 'eurocêntrica', considerando como 'eurocêntrica' as tradições decorrentes da Europa e regiões, nas quais houve o advento da ciência moderna a partir do Século XVII. Assim foi, a exemplo, com a transmissão de todo o conhecimento produzido pelos gregos, resgatado, acrescido e transmitido ao mundo pela Casa de Sabedoria dos persas e, posteriormente, excluído da história da ciência.

A Casa da Sabedoria teve importante papel em preservar e transmitir ao Ocidente obras da antiguidade. Fundada em 750 na dinastia Abássida, governante do império islâmico, promovia: a tradução de trabalhos em grego, chinês, sânscrito, persa e de outras línguas; a construção de grandes bibliotecas; o acolhimento de intelectuais perseguidos pelos imperadores bizantinos. As atividades da Casa da Sabedoria eram patrocinadas por uma grande quantidade de papelarias, que chegaram a vender milhares de livros por dia. Graças a ela, Bagdá tornou-se o maior centro educacional entre os séculos IX e XIII. atraiu muitos estudiosos, filósofos e escritores, poetas e artistas, astrólogos astrônomos, matemáticos, geógrafos, zoólogos, médicos, químicos alquimistas. Naquela academia, reuniam-se todos os dias a fim de traduzir, ler, escrever, debater e para compartilhar informação, ideias e cultura (LYONS, 2011). Isto se deu com a filosofia, com a sociologia, com a astronomia e astrologia, com a ciência médica, com a poesia e artes em geral. Daí, suprimiu-se do mundo civilizado as raízes e as variáveis formas de produção e de elaboração do conhecimento, com destaque para a extinção da Casa da Sabedoria. Esse movimento transversal de supressão epistemológica também é longitudinal, ou seja, há, sobretudo, causas ideológicas. Dos gregos aos europeus, pôs-se em hiato a contribuição dos árabes em suas casas de sabedoria. Dos europeus às suas colônias e ex-colônias, suprimiu-se inúmeras contribuições de outras formas de conhecimento com origem nos saberes tradicionais de povos aborígenes e nos saberes autóctones de povos nativos.

Partindo da premissa de que não há epistemologias neutras e que a reflexão nesse campo deve se basear não em abstrações, mas nas práticas de conhecimento e seus impactos nas práticas sociais, Santos (2009) afirma que toda experiência social produz e reproduz conhecimento e, com efeito, diversas epistemologias. Aquelas tidas como hegemônicas são decorrentes do impacto do colonialismo e do capitalismo onde se estabeleceram para além da dominação econômica mensurável. São as ideologias dominantes que configuram a dominação epistemológica numa 
relação desigual de "saber-poder" levando ao desaparecimento ou a subalternidade, muitas formas de saber autóctones, populares, tradicionais. Considerado modelo único, o processo civilizatório inaugurado na Europa e validado nas instituições de ensino das ex-colônias atuam reproduzindo formas de distinção com base em preconceitos de sociedades brancas, cristãs, burguesas, cultas, "civilizadas", baseadas em critérios estreitos de desenvolvimento, marcadas pela modernidade e pelo capitalismo.

Esse processo de reprodução das relações de domínio e exploração nomeado colonialidade, dá-se nas ex-colônias da Europa desde que foram inculcados na subjetividade coletiva crenças, valores e normas da ideologia imperial. Figueiredo (2012) considera que a colonialidade incide tanto no macro quanto no micro social. Compromete política, economia, cultura, ecologia, ciência, arte, religiosidade, relações cotidianas, familiares e sociais em geral e, ao afetar as relações de poder ressoa intensamente nas relações de saber.

Com efeito, a colonialidade formata as instituições de ensino superior brasileiras em geral estruturadas para reproduzir relações de poder e de saber de forma que não só deixam na invisibilidade parcelas significativas da população universitária, tais como pessoas de origem negra, indígena e nativas em comunidades tradicionais, como os saberes e valores provindos de meios populares. A educação e suas instituições a partir da colonialidade, trazem o eurocentrismo como referência hegemônica para a metodologia científica da ciência moderna, para o discurso da verdade científica. Os discursos são determinados por regras sociais dos que detém o saber imposto como verdadeiro (FOUCAULT, 1996). Mais que isso, o discurso da verdade científica hierarquiza as formas de conhecimento, determinando tal ciência como a verdade, seguida de longe por outras formas de produção de conhecimento, religião, experiência de vida e bom senso, memória, saberes locais, arte, num patamar inferior de credibilidade e daí exercem o controle da subjetividade/intersubjetividade. Ainda de acordo com Figueiredo (2012), é no corpus colonializante que se encontra o procedimento classificatório, hierarquizante, excludente, como mecanismo articulador da ação de colonializar, que implica em oprimir, subalternizar, explorar, desumanizar, coisificar, tornar o indivíduo não humano, torná-lo coisa de uso - nas palavras do autor, para um propósito alheio a ele mesmo.

Todo o arcabouço colonializante mantém e reforça as estruturas de exploração capitalista e exclusão neoliberal que é reproduzido pelo sistema educacional. Tolovi (2018, p. 137) considera que "não podemos perder de vista o fato de que a disputa pelo domínio do sistema educacional está ligada a um plano bem maior e muito bem arquitetado. E este possui como pano de fundo 
uma dimensão ideológica que precisamos evidenciar. Afinal, se preparamos nossas crianças, adolescentes e jovens para o mundo do trabalho, retirando direitos dos trabalhadores e trabalhadoras, vamos precisar da moral e da religião para evitar a rebeldia descontrolada. Tal foi a estratégia utilizada pelos colonizadores ao chegarem ao Brasil."

Catherine Walsh no artigo Interculturalidad, colonialidad y educación (2007) indaga sobre formas de ação e intervenção em ações coletivas com responsabilidade política, epistemológica e ética para superação da colonialidade. Ou seja, a colonialidade do poder abrange a colonialidade do saber e a esse escopo a autora contrapõe a proposta da interculturalidade crítica como dimensão essencial da pedagogia descolonializadora.

Ao que perguntamos sobre o que fazer para transformar as escolas em espaços dinâmicos rumo a um lugar dialógico na expressão de práticas interculturais críticas que sonhamos. Há embutida nessa questão uma necessidade de se compreender as geopolíticas do conhecimento e seus padrões de poder como um sistema hierárquico de racionalização do ser, do saber e do saber fazer, além do que, não basta compreender, pois a superação da colonialidade implica entendimentos que fundamentam propostas para uma educação diferenciada, voltada para a ecologia dos saberes, ou seja, para a construção de processos educativos interculturais críticos e dialógicos. O que nos leva a pensar que essa interculturalidade-descolonialidade, como projeto político epistêmico, consiste no reforço cultural autóctone tanto no ensino básico como no ensino superior.

Catherine Walsh (2007, on line) cita Juan García na abordagem da interculturalidade como principio ideológico que aponta a transformação das atuais estruturas, instituições e formas de relações na sociedade voltada ao advento de poderes locais alternativos, um Estado plurinacional e uma sociedade distinta, ao que esse autor nomeou como "casa adentro y casa afuera" (para dentro de casa - da casa para fora). "La casa adentro" indica os processos internos das organizações, principalmente das comunidades, para construir e fortalecer seu próprio pensamento e conhecimento. Esses processos apontam para a recuperação do conhecimento que tem sido considerado pela sociedade como não-conhecimento, conhecimento presente na memória dos sábios e dos idosos, e na filosofia e cosmologia cujas raízes se encontram ancestralidade, mas também na natureza e na vida cotidiana. Contra os tantos efeitos perversos da colonialidade, destacam-se as lutas reivindicatórias de questões de gênero, contra o racismo e contra todas as formas de desigualdades sociais.

$\mathrm{Na}$ história recente de países do leste e do oeste, no que se convencionou chamar de 
ocidente e oriente, tem havido movimentos ultra conservadores, reacionários, racistas, xenófobos e homofóbicos de dimensões que cada vez mais ampliam as desigualdades sociais. Há inúmeros exemplos que ilustram essas situações, tais como: os movimentos xenófobos ascenderam na Europa em 2015; o retrocesso em equidade étnica e de classes a partir de golpes de estado e ascensão de governos de direita na América Latina desde 2015; as marchas racistas e neonazistas acontecidas nos Estados Unidos em 2017.

Os problemas sociais geram, e são gerados, em conflitos que implodem unidades sociais e causam anomia. Na etimologia anomia significa lei. Em Ciências Sociais, anomia é um conceito que inclui, além de leis, normas e práticas sociais. Como consequência da modernidade, a anomia mina valores sociais provocando vazios de significado nos indivíduos e perda de identidade coletiva. Para Peter Berger (1985) nomos é o mundo humano que tem sentido de enfrentamento ao caos. A sociedade mantem o nomos dando sentido à realidade humana. Na ausência de leis que valam para todos, de respeito às normas e de solidariedade, a sociedade mergulha na anomia, ou seja, no caos. Ideologias subjugadoras, que se expandem e minam a confiança nos destinos coletivos, surgem quando indivíduos e grupos agem para impor modelos de interação individual e grupal, que satisfazem apenas aos que detém os capitais simbólicos. Consideramos aqui que os “donos do poder" são elites constituídas por parcelas da população que concentram em pequenos segmentos as riquezas sociais nomeadas capitais simbólicos, ou seja, a reserva de domínio das trocas de bens econômicos, interacionais, artísticos, culturais e de saberes sociais (BOURDIEU, 1998; 2004.).

Igualmente danoso para coesão social e grupal é o comportamento reacionário. Como um inseto que resistisse a trocar de casca para crescer, nesse padrão de atuação pública se olha para trás enquanto se caminha para frente, ou seja, indivíduos e grupos querem replicar o passado, atuam tentando fazer com que a sociedade do presente e do futuro seja algo que já foi, desconhecendo e negando as novas necessidades, novos desafios e novos contextos de relações entre grupos, povos e nações. Como se estivessem olhando para as sombras no fundo de suas cavernas, considerando essas a única e real forma de viver, são velhos de ideias, com medo do novo e dos jovens. Fogem do diálogo e buscam impor à sociedade normas e leis que minam qualquer possibilidade de equidade, justiça social e adaptação coletiva às exigências da vida contemporânea. No Brasil, essa onda reacionária se intensificou no momento político social de hoje, cujas articulações fascistas locais aliadas a interesses imperialistas neoliberais depuseram a presidente Dilma Roussef (2016) e encarceraram o ex-presidente Lula (2018). O eco do golpe 
jurídico midiático reverbera nas instituições sociais, nas religiões, na família, nas escolas, nas empresas midiáticas e nos partidos políticos. Agridem moral e fisicamente a tudo e a todos que desejam o novo integrativo nos seus pensamentos, nas suas emoções, nos seus corpos, nas suas relações e que expressem publicamente culturas autóctones como necessidade de valores de alteridade, equidade e justiça social (CORDEIRO, 2018). E, retroalimentam o ataque à conquista de direitos dos segmentos e classes sociais historicamente subjugados. Nesse mesmo período eclodiu, como uma onda vinda da Idade Média, e assolou o Brasil via mídia televisiva, internet e movimentos patrocinados por grupos e partidos políticos, numa espécie de conservadorismo reacionário com a pretensão de instalar um discurso cujo centro seria o "ataque à família". Algo muito semelhante ao que aconteceu em 1964 a partir do golpe de estado no Brasil.

\section{Método}

Ressaltando o aspecto teórico-metodológico, consideramos que, de maneira geral, a universidade pública espelha o que acontece na sociedade em que ela está inserida, tanto do ponto de vista político quanto social. Para os que atuam em educação acreditando que ela pode ser libertadora, a noção fundamental de uma pedagogia crítica-educativa compreende respeito, alteridade, empatia e diálogo. Parte dos integrantes da universidade sugerem horizontes de entendimento social, às vezes de forma organizada por meio de debates e manifestações, outras vezes de forma espontânea, aparentemente caótica, com performances e intervenções estéticas, sobretudo, entre os(as) estudantes que são jovens. Quando se discute sobre jovens é necessário lembrar que existem inúmeras juventudes, variando de classes sociais, etnias, regiões etc.

Em todas as Ciências Sociais, não há um consenso em torno de um conceito único e geral sobre juventude (ROMERO, 2008). Juventude pode ser definida como uma categoria etária ou como categorias geracionais e sociais que pode ser entendida ora como uma unidade, ora como pluralismo (BOURDIEU, 1983; PAIS, 2003). Por isso aqui nomeamos genericamente no plural “juventudes”. As juventudes que vivem na universidade pública no Brasil, de maneira geral, carecem de meios para se expressarem e serem contempladas em suas demandas. Uma forma bastante frequente de expressão dos jovens na universidade se dá pelas pichações. Picha-se por protesto, para divulgação e para extravasar indignação, além de ser uma manifestação de disputa pelo espaço. Em qualquer dos casos, as pichações são gritos reprimidos de jovens expressos em 
intervenções visuais que têm acontecido nas paredes dos diversos campi da Universidade Regional do Cariri, URCA. A partir dessas reflexões, duas inquietações nos mobilizaram: Como inserir propostas dialógicas interculturais na educação? Como transformar a escola pública num espaço de expressão da interculturalidade crítica? Refletindo sobre essas questões tomamos o trabalho com murais, realizado recentemente na Universidade Regional do Cariri, URCA, Campus Pimenta, em Crato, Ceará, como uma situação específica de atuação coletiva inspirada na proposta da interculturalidade crítica. A URCA, formada por aproximadamente 10 mil alunos, 600 professores e trezentos servidores, tem sido palco de vários conflitos. No Campus Pimenta, as paredes têm sido continuamente pichadas. As pichações são clandestinas, às vezes de maneira elaborada com conteúdos étnicos, pela liberdade sexual, igualdade de gênero; contra o racismo, a misoginia e homofobia; outras vezes são aleatórias com palavras de ordem, provocações ao poder estabelecido, protestos contra a administração, contra o governo federal, contra o sexismo e insultos. As pichações têm gerado uma disputa pelo espaço visual. A administração dos campi pinta inúmeras vezes as fachadas externas e internas de verde bandeira e amarelo, com as paredes intermediárias de branco e "cinza oficina". Surgem novas pichações. A administração repinta sobre as pichações. Os pichadores voltam a pichar. Entretanto, os poucos grafites tem sido preservados da ação de ambos, pichadores e administração. Ao andar pelos corredores internos, as paredes explodiam conflitos e efeitos de ausência do diálogo, recobertos por inúmeras camadas de tinta e continuamente reescritas. 
Figura 1: Exemplos de pichações no Campus Pimenta - URCA
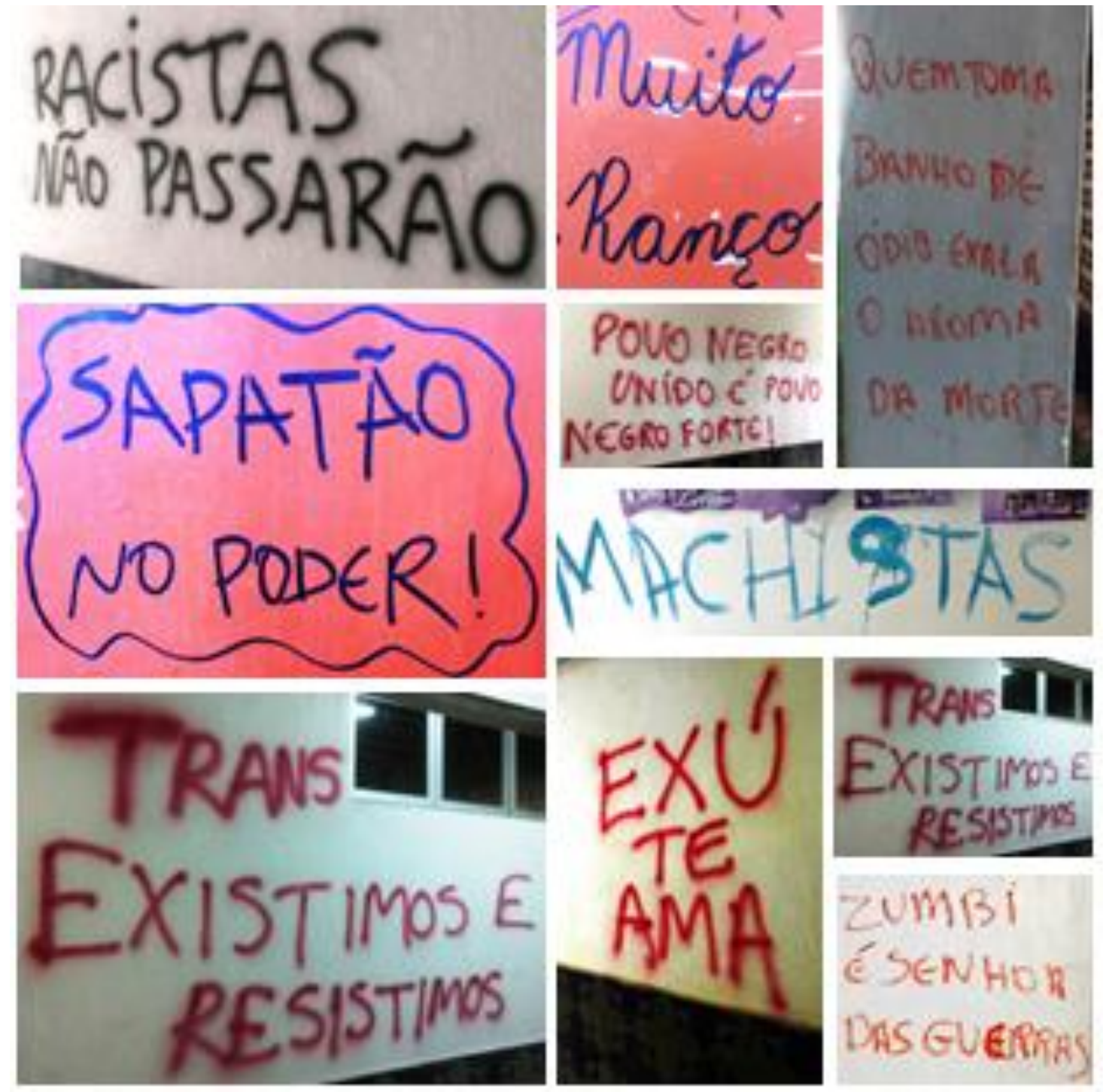

Autoria das fotos: Domingos Sávio Cordeiro

Provocados por essa situação imaginamos uma atuação que propusesse uma alternativa de debate via realização de murais nas paredes do campus Pimenta da URCA, em Crato. Considerando o papel educativo que pode surgir de uma ação coletiva, para além da disputa entre o domínio do espaço visual pela administração e pichadores, propusemos uma intervenção estética.

A dimensão estética dos trabalhos realizados em uma das linguagens das artes visuais, os murais, são aqui considerados primordialmente como estética cognitiva, ou seja, do ponto de vista 
da sociologia há um paradigma científico emergente. Nele, a dimensão ativa da transformação do real está subordinada a contemplação do resultado, no sentido de que "a qualidade do conhecimento afere-se menos pelo que ele controla ou faz funcionar no mundo exterior do que pela satisfação pessoal que dá a quem a ele acede e o partilha" (SANTOS, 1998, p. 54). Tanto a estética como o senso estético podem ser considerados marcadores sociais no que diz respeito a disputas entre classes e tensões que se manifestam nos grupos e segmentos que formam um espaço social. Corroboramos com Simmel (2010) que considera a questão social não somente como uma questão de ética, mas também de estética. Para este autor o apelo de atração estética em um trabalho relaciona-se a sua representação ao trazer uma economia de forças para o pensamento, permitindo veicular um máximo de representações com um mínimo de esforço. Além disso, “todas as multiplicidades e todas as contradições do desenvolvimento histórico se refletem na amplitude do nosso sentimento estético, capaz de ligar a mesma força de atração a cada um dos pólos opostos dos interesses sociais (SIMMEL, 2010, p. 7).

Em relação a aspectos da metodologia operacional, convidamos pichadores para fazerem intervenções orientadas e mais elaboradas e comunicamos nossa intenção à administração. Então criamos uma campanha cujo mote foi "Grafite Tolerância". Pedimos à comunidade que considerasse, primeiramente, a tolerância estética. Porque nessa proposta havia uma grande quantidade de formas expressivas e estilos. Além do que, frequentemente, a tolerância estética tem o sentido de suportar algo que não se quer em qualquer de suas formas. Tolerância para aceitar os grafites tanto por parte da administração, quanto pelos pichadores porque os grafites são obra de arte genuína. São expressões abnegadas da arte urbana contemporânea, produto da intervenção pública de artistas que se esmeram numa expressão estética mais elaborada e de pessoas que, não dispondo de habilidades técnicas sofisticadas e treinamento estético aprimorado, se aventuram na experimentação de uma manifestação visual. O que mais nos interessava era que cada pessoa inscrita representasse visualmente a necessidade de tolerância no momento atual. Em segundo plano, o mote tolerância também traz visibilidade à necessidade urgente de compreensão sobre a alteridade, que é a capacidade de reconhecer o(a) outro(a) na plenitude da sua dignidade, dos seus direitos e, sobretudo, da sua diferença.

Em síntese, a tolerância é um convite fundamental à aceitação ou respeito às diversidades racial, étnica, geracional, religiosa, sexual, de gênero e regional que compõem a sociedade brasileira. A cada participante solicitamos que se inspirasse no contexto de intolerância crescente na sociedade brasileira e na necessidade de respeito ao direito do(a) outro(a) ser como é e no 
diálogo, ou seja, como aceitação perante a diversidade absolutamente necessária à resiliência humana ou de qualquer espécie. A metodologia inspiradora aqui foi uma adaptação do que é empregado em pesquisas com representação social. De maneira didática, pode-se dizer que uma representação social atua como um modo de interpretação da realidade que constitui a visão de mundo, determinando comportamentos e práticas de indivíduos e grupos. Há dois grupos de métodos para produção de dados com representações sociais: métodos interrogativos - entrevistas, questionários e suportes gráficos -, e métodos associativos - evocações, associações livres e mapas associativos (SÁ, 1996, p. 107).

No humano, a prática da tolerância nessa perspectiva pode levar à empatia, como patamar mais elevado de interação social e grupal. Utilizamos como pergunta geradora a indagação: "que imagem lhe vem à mente quando eu falo a palavra tolerância?”. Em seguida pedíamos um esboço e íamos conversar sobre a proposta visual e a ideia por trás.

Inicialmente conseguimos autorização para pintar 14 paredes internas dos prédios medindo de um a 60 metros quadrados cada. Fizemos divulgação via cartazes e redes sociais. Alunos da universidade começaram a participar. Depois vieram professores e alunos de outras universidades e do ensino médio. Grafiteiros profissionais, muralistas e pichadores também chegaram. Ao todo participaram 42 artistas autores e 15 artistas no apoio. Usaram várias técnicas: spray, acrílica, óleo, carvão, caneta piloto, caneta posca, guache, lã sobre tela de aço e "lamb".

\section{Resultados e Discussão}

Entre outubro de 2017 e janeiro de 2018 conseguimos ampliar o espaço inicial previsto de 14 grafites para 64 murais que, depois de concluídos, não passam despercebidos.

\footnotetext{
Desloco-me pelo Campus do Pimenta da URCA e vejo enormes painéis que tomam paredes inteiras com muita arte e a perspectiva de que é possível construir um mundo diferente daquele que até aqui realizamos. Sob um sol da tarde, com uma temperatura que beira os 35 graus Celsius, a estudante coloca seu material no chão e vai aos poucos retomando o trabalho que vem desenvolvendo há mais de uma semana. Parece ter pressa em manifestar todo o seu sentimento. Duas negras, uma frontal outra de perfil, uma com turbante outra sem ele, expressam a mensagem "a luz da minha luta sua bala não apaga”. Vez por outra um para, olha, pergunta algo e passa, não sem olhar algumas vezes para contemplar a beleza da artista expressa na arte de fazer-se estudante, e ser futura professora. Outros chegam, elas, eles, eles que são elas, elas que são eles, que nem se preocupam com as classificações de gênero, que só querem ser felizes, "trocam uma ideia" sobre o painel com mais de 2,0 por 3,0 metros, qual tinta, onde carrega mais, onde alivia. (MELO, 2018).
} 
Figura 2: Exemplos de grafites realizados no Campus Pimenta - URCA
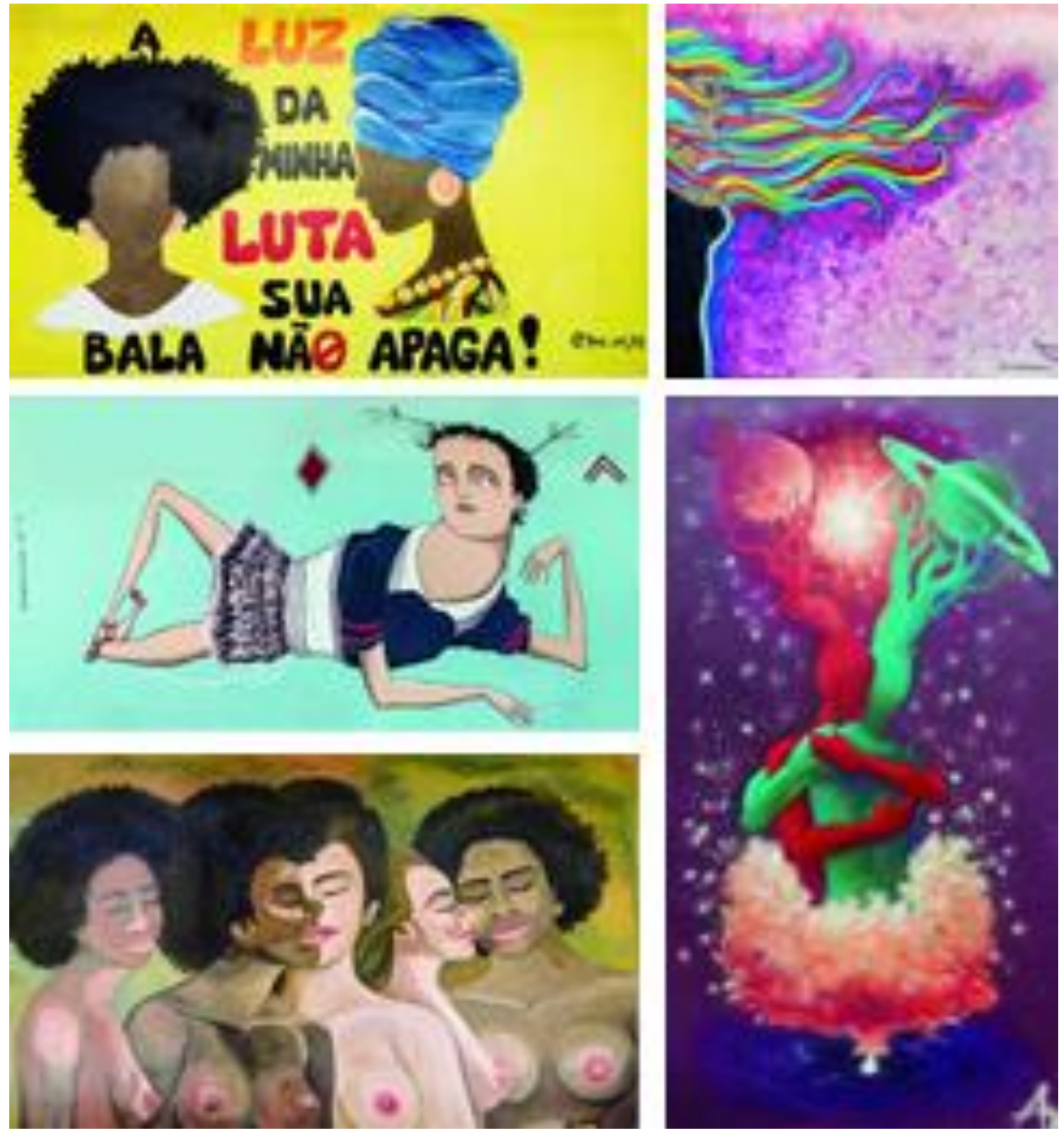

Autoria das fotos: Amilton Duarte

Grafites podem gerar impactos. Se "feios" para uns, "bonitos" para outros. Podem ser expressão de subjetividades individuais ou de anseios coletivos. Podem trazer a tona conflitos, problemas sociais ou ainda, esperanças. Realizado em qualquer de suas técnicas, faz parte da paisagem urbana. Araújo (2018) afirma que mesmo uma cidade cinza, com muros cheirando à tinta e câmeras de vigilância, "terá sua normalidade perfurada como uma planta que cresce na rachadura de uma parede e coloca em evidência as falhas de todo o processo de construção e de 
manutenção de uma obra" (2018, p. 125). Dessa forma os grafites expõe as "rachaduras sociais", os discursos "invisibilizados," ao mesmo tempo que revelam demandas por mudanças que não podem ser ignoradas.

Entrevistamos todos(as) os(as) participantes após a realização de cada grafite. Destacamos alguns trechos de depoimentos que põe em evidência o efeito de conexão consigo mesmo(a) em decorrência da realização das pinturas e positividade em relação ao contexto em que vive:

Cara, esse movimento me salvou. Eu não sabia como ia terminar o semestre, eu estava pirando (M.L.S., 21).

"Salvou" no sentido terapêutico porque para o estudante, autor do trabalho, encontrou na pintura um meio de fazer fluir sua indignação e sua identificação cultural.

Eu não consigo descrever o que eu estou sentindo... É surreal. Se eu falar muito, vou chorar. Isso está acontecendo de verdade! Ter um desenho estampado na parede da URCA, porque a URCA mudou minha vida! Meu Deus! Tá sendo uma loucura, tá um borbulhão de sentimentos, está tudo misturado (F. S., 23).

O que emerge no trecho acima é o entusiasmo com o discurso impresso na parede, prenhe de paixão e significados autobiográficos.

Estas narrativas a seguir trazem em subtexto as demandas por equidade, pela superação de preconceitos e obsoletos padrões de convivência, além de afirmações de autoestimas que se elevam a partir da realização das obras.

Estou curtindo bastante e estou muito empolgado. Ficamos trabalhando bem, nem nos lembramos de comer, nem de horários de nada (B. S., 28).

O projeto é importante para que as pessoas comecem a enxergar o grafite com outros olhos mostrando que a arte de rua também é arte e merece reconhecimento do seu valor, além de estampar nos muros da universidade as nossas lutas diárias contra o racismo, machismo, "lgbtfobia" e intolerância religiosa (D. A., 24).

Somos iguais, a gente tem cor, a gente tem osso, a gente tem coração. A gente tem funções. A gente é um organismo vivo. E isso deveria fazer com que a gente pensasse da maneira de respeitar igual uns aos outros, sabe? A gente vira tudo pó e vai pra terra, e acaba que é o mesmo fim pra todo mundo (A.S., 26).

A tolerância vai de cada um. Porque passar tolerância numa imagem tem um peso, mas, se aquilo não entra na consciência de alguém, não adianta de nada. Você tem que estar com a pretensão de mudar a si mesmo, de melhorar a si mesmo. A imagem vai dar só o caminho para você absorver a informação. Evoluir como ser humano depende de você (A., 25).

Ademais, algumas cenas revelaram uma sensação de alívio sentida por participantes. Em 
uma entrevista, um rapaz contara o quanto tinha sido reprimido em sua infância por conta de ser homossexual. Ele foi surrado para "aprender a ser homem". Após terminar sua pintura, observamos durante vários dias às tardes que ele chegava e sentava em um banco em frente à pintura que fez e ficava admirando-a. Parecia-nos que alguma coisa dentro dele havia mudado após realizar aquele trabalho. Estava mais tranquilo e feliz. Outros participantes tiveram atitudes semelhantes, voltavam para observar longamente o que tinham feito, revelando o efeito subjetivo e discursivo como um dos recursos de atuação pública na realização de grafites. Servindo uma nova estética que dá prazer aos olhos ou inquieta, a interculturalidade se expressa com todo o potencial de transmitir códigos de vida, visões de mundo e maneiras de viver.

\section{Conclusão}

Parafraseando Walsh (2007), inserir uma mudança decolonial em torno da educação requer atenção às intervenções que podemos empreender para construir e gerar consciência política, confrontando a hegemonia e tornando visíveis as subjetividades nas práticas pedagógicas. Embora o nosso desejo seja que as obras continuem preservadas por bastante tempo para que, como conjunto artístico cultural inédito, possa cumprir todo o potencial educativo das suas composições, cores e formas, temos que aceitar sua efemeridade. Ao baterem as chuvas mais fortes o "lamb" dilui. O sol escaldante sequestra os pigmentos. Pessoas não participantes da campanha, mas que frequentam a universidade, sentem-se incomodadas com alguns trabalhos e os sabota raspando, escrevendo em cima ou jogando tinta. É a presença do fator palimpsesto informando que no espaço público as normas são flexíveis, subvertendo o institucional.

Ao final, quando encerramos a Campanha Grafite Tolerância no Campus Pimenta da URCA percebemos uma curiosidade alegre nas pessoas que visitam o prédio. Professores com suas classes do Ensino Básico continuamente vêm apreciar os trabalhos. Grupos da graduação e da pós-graduação debatem sobre as obras. Pessoas vêm fotografar e fazer selfies naqueles trabalhos que mais gostam.

Os problemas sociais continuam refletindo no dia-a-dia da universidade, mas o clima mudou. Surgiu um lugar, ora de contemplação, ora provocativo ao diálogo. Inicialmente tais espaços contribuem como canais para fortalecimento de referências de grupos sub representados na linha do olhar onde costumeiramente tudo é propaganda ou catarse. Agora as obras nessas 
paredes formam um conjunto cultural. Como categoria o conjunto cultural insere-se na tendência já consolidada nas Ciências Sociais em buscar respostas às suas indagações abraçando perspectivas analíticas compreensivas das subjetividades e especificidades locais. $\mathrm{Na}$ universidade, em meio às juventudes, em ambientes cuja formação da sociedade é fruto de inúmeras influências migratórias, étnicas e linguísticas, entre outras, há, certamente, inúmeros conjuntos culturais. ${ }^{1}$

Pensar em conjunto cultural leva-nos a uma noção que traz inúmeras possibilidades de interpretação a partir da observação de seus componentes: religiosos, de gênero, de sexo, étnicos, de classe, sócio-ambientais e linguagem. Eventualmente um observador desses trabalhos possivelmente terá a impressão de haver conflitos entre eles. Há obras que aparentemente nada tem a ver com outras. Mas um olhar mais atento poderá tratá-los como um conjunto artístico cultural integrado, ou seja, uma coleção de elementos que partilham uma temporalidade e podem ser historicamente determinados na trajetória de um grupo ou sociedade. Eles tanto podem se originar de maneira independente e autóctone, quanto por intercâmbio de influências e compartilhamento de traços culturais, tais como: linguagem; arte, práticas de trabalho; relação com o meio ambiente; histórias, contos; modos de vida importados e adaptados; costumes; ideias e referências, corporificados em artefatos, em expressões estéticas ou praticadas em costumes e na fala. Do ponto de vista da participação individual e expressão coletiva os trabalhos se equivalem, dialogam entre si, são registros de uma geração. Como conjunto cultural, os murais realizados são uma conquista coletiva da expressão visual continuada de ícones das gerações jovens que participam da/na universidade.

Paulo Freire (1976) afirma que as práticas culturais tem sentido de ação para a libertação dos oprimidos caracterizada pelo diálogo que é o fundamento do conhecimento. Como sugestão fazemos coro com a indicação da escola freireana que o saber, fruto da dialogicidade, constitui a própria intersubjetividade humana, sendo ela relacional e consubstanciadora da democracia, da alteridade, no afeto, na fé, na humildade de saber-se inacabado e histórico. Como afirma Figueiredo (2007, p. 40-41), “o diálogo gera caminhos muito mais efetivos/afetivos que os rígidos limites impostos pela educação bancária, ainda hegemônica na educação escolar onde se cultuam as "ciências modernas".

A substância de uma cultura são os meios de que se dispõe para ter experiências e viver

\footnotetext{
${ }^{1}$ Sobre a utilização da noção de conjunto cultural como categoria analítica, ver: Boas, 2004. Sobre a aplicação dessa categoria em pesquisa com culturas populares e tradicionais ver: Cordeiro, 2011.
} 
significados do mundo. Assim, assumimos que todos(as) podemos nos expressar pela arte e passamos a estimular as pessoas convidadas a acreditar que conseguem expor suas angustias, desejos, esperanças e leituras de mundo, ainda que só por rabiscos como fazem muitos que picham. Podemos ensaiar o aprender - ensinar dialógico nesse diálogo com essas artes de se fazer ser livre... Outras lições ali se encontram.

O nosso aprendizado de processos educativos dialógicos, decolonializantes, nesta trajetória, se encontra também na disposição para acreditar nas pessoas jovens, abrindo-lhes espaço para significação de suas experiências, esperando delas o melhor na expressão de suas culturas. Senão, também pela promoção da interculturalidade crítica, como superar os grilhões colonializantes?

\section{Referências}

ARAÚJO, A. O. Muros que falam: narrativas do graffiti contemporâneo. In: CORDEIRO, D. S. (coord.). Grafite Tolerância. Crato: EDURCA, 2018. P. 124-5

BERGER, P. O dossel sagrado. São Paulo: Paulinas, 1985.

BOAS, F. Antropologia cultural. Org. Celso Castro. Rio de Janeiro: Zahar, 2004.

BOURDIEU, P. A juventude é apenas uma palavra. In: Questões de Sociologia. Rio de Janeiro: Marco Zero, 1983.

O poder simbólico. 2 ed. Rio de Janeiro: Bertrand Brasil, 1998.

- Organização Sérgio Micelli. A economia das trocas simbólicas. 5 ed. São Paulo: Perspectiva, 2004.

CORDEIRO, D. S. Narradores do Padre Cícero: muito mais a contar. Fortaleza: Expressão, 2011.

CORDEIRO, D. S. Introdução. In: . (coord.). Grafite Tolerância. Crato: EDURCA, 2018. P. 1518

FIGUEIREDO, J. B. Educação ambiental dialógica: as contribuições de Paulo Freire e a cultura sertaneja nordestina. Fortaleza: UFC, 2007.

FIGUEIREDO, J. B. Paulo Freire e a descolonialidade do saber e do ser. In: FIGUEIREDO, J. B.; SILVA, M. E. H. (Org.). Formação humana e dialogicidade III: encantos que se encontram nos diálogos que acompanham Freire. Fortaleza: UFC, 2012. P. 66-88. 
FOULCAUlT, M. A ordem do discurso; aula inaugural no Collège de France. São Paulo: Edições Loyola, 1996.

FREIRE, P. Ação cultural para a liberdade e outros escritos. Rio de Janeiro: Paz e Terra, 1976.

LYONS, J. A Casa da Sabedoria; como a valorização do conhecimento pelos árabes transformou a civilização ocidental. Rio de Janeiro: Zahar, 2011.

MELO, F. E. O grafite da tolerância. In: CORDEIRO, Domingos Sávio (coord.) Grafite Tolerância. Crato: EDURCA, 2018. P. 09-14

NASCIMENTO, C. C. Reflexões sobre a natureza da ciência à luz das Epistemologias do Sul. XI Encontro Nacional de Pesquisa em Educação em Ciências - XI ENPEC, Universidade Federal de Santa Catarina, Florianópolis, SC - 3 a 6 de julho de 2017. Disponível em: 〈http://www.abrapecnet.org.br/enpec/xi-enpec/anais/resumos/R2597-1.pdf> Acesso em: 02 abr. 2018

PAIS, J. M. Culturas juvenis. Lisboa: Imprensa Nacional da Casa da Moeda, 2003.

ROMERO, G. M. Interpretando o que se diz sobre jovens: um ensaio crítico. Verinotio - Revista Online de Educação e Ciências Humanas. Nº 8, Ano IV, maio de 2008 - Publicação semestral. Disponível em:

<http://www.verinotio.org/conteudo/0.62499424500856.pdf. ISSN 1981-061X> Acesso em: 25 mar. 2018.

SÁ, C. P. Núcleo central das representações sociais. Petrópolis: Vozes, 1996.

SANTOS, B. S. Um discurso sobre as ciências. 10 ed. Porto, PT: Afrontamento, 1998.

Para além do pensamento abissal: das linhas globais a uma ecologia de saberes. In: SANTOS, Boaventura de Sousa; MENESES, Maria Paula (Orgs.). Epistemologias do Sul. Coimbra PT: Almedina, 2009. P. 23 seq.

GEORG, Simmel. Estética e sociologia. Tradução Simone Carneiro Maldonado

Disponível em:

<https://ideiasconcretas.files.wordpress.com/2010/05/estetica_e_sociologia_georg_simmel.pdf> Acesso em: 23 mai. 2018

TOLOVI, C. A. Para além da tolerância. In: CORDEIRO, Domingos Sávio (coord.). Grafite Tolerância. Crato: EDURCA, 2018. P. 136-141

WALSH, C. Interculturalidad, colonialidad y educación. In: Revista Educación y Pedagogía, vol. XIX, núm. 48, mayo - agosto de 2007. Disponível em:

http://www.flacsoandes.edu.ec/sites/default/files/agora/files/1265909654.interculturalidad_colonial idad_y_educacion_0.pdf. Acesso: 03 abr. 2018 